\section{Commentary: Risky business}

\author{
Kathryn E. Engelhardt, MD, MS, and \\ Benjamin D. Kozower, MD, MPH
}

Patients with early-stage lung cancers have many treatment options available to them in the current era, including lobectomy, segmentectomy, wedge resections, radiation therapy, and other ablative therapies. As such, shared decision-making becomes increasingly important; understanding the patient-specific risk of an intervention will inform these decisions. The American College of Surgeons (ACS) draws on nationwide pragmatic data to develop their evolving National Surgical Quality Improvement Program (NSQIP) calculator, which is an online tool that provides predictions of various outcomes (such as length of stay, death, pneumonia, and others) based on an individual patient's characteristics and potential procedure. ${ }^{1}$

In this issue of the Journal, Chudgar and colleagues ${ }^{2}$ report on the experience at Memorial Sloan Kettering using the ACS NSQIP calculator for patients undergoing pulmonary resections. They compared the observed outcomes from their institutional database to those predicted by NSQIP. In general, their study demonstrated good discriminatory and calibration performance of the NSQIP risk calculator for their patient population, except for a few discrete areas (poor discriminatory performance for readmission; poor calibration for renal failure, discharge to nursing home or rehabilitation, and sepsis).

These findings should be interpreted in the proper context. It is important to understand how cases are submitted to ACS for inclusion in the NSQIP modeling.

\footnotetext{
From the Division of Cardiothoracic Surgery, Department of Surgery, Washington University, St Louis, Mo.

Disclosures: The authors reported no conflicts of interest.

The Journal policy requires editors and reviewers to disclose conflicts of interest and to decline handling or reviewing manuscripts for which they may have a conflict of interest. The editors and reviewers of this article have no conflicts of interest.

Received for publication Feb 1, 2021; revisions received Feb 1, 2021; accepted for publication Feb 1, 2021; available ahead of print Feb 5, 2021.

Address for reprints: Benjamin D. Kozower, MD, MPH, Division of Cardiothoracic Surgery, Department of Surgery, Washington University, One Barnes-Jewish Hospital Plaza, Suite 3108 Queeny Tower, St Louis, MO 63110-1013 (E-mail: kozower@wustl.edu).

J Thorac Cardiovasc Surg 2022;163:1518-9

$0022-5223 / \$ 36.00$

Copyright (c) 2021 by The American Association for Thoracic Surgery

https://doi.org/10.1016/j.jtcvs.2021.02.002
}

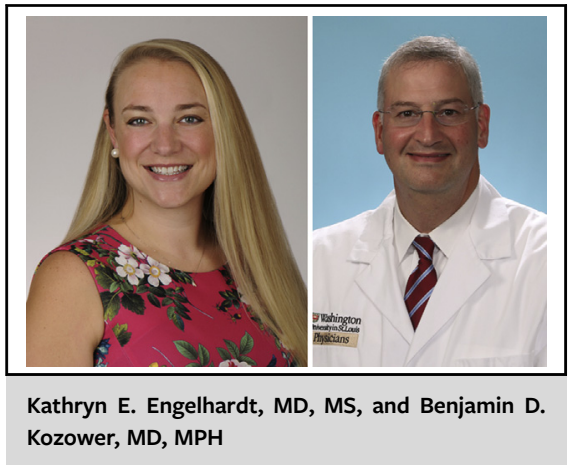

CENTRAL MESSAGE

Shared decision-making requires an accurate understanding of the risks involved with each treatment option. Chudgar et al evaluate a useful tool for patients undergoing pulmonary resection.

Centers must participate in the program, which comes at a significant fee, and thus is limited to centers with an ideologic and financial penchant for quality improvement. Each of these centers contribute at least $10 \%$ of a random sample of cases but can submit as many cases as they want if the hospital, for example, is targeting a specific service line for improvement and want improved data analysis for that group of cases. Therefore, there is the potential for overrepresentation of either hospitals who have identified pulmonary resections as an opportunity for improvement or alternatively by hospitals with the resources to dedicate additional abstractor time to pulmonary resections. While this calculator performed well for the reported patient cohort, an ideal calculator would be built based on either a $100 \%$ sample of cases or on a sample known to be representative of the cohort to which it will ultimately be applied. As mentioned by the authors, an ideal calculator for pulmonary resection would include input variables such as pulmonary function as well as outcomes such as prolonged air leak and postoperative atrial fibrillation. In summary, this analysis shows the ACS NSQIP calculator can be used to guide shared decision-making discussions, but there is still room to improve predictive modeling for the general thoracic surgery patient population. 


\section{References}

1. Bilimoria KY, Liu Y, Paruch JL, Zhou L, Kmiecik TE, Ko CY, et al. Development and evaluation of the universal ACS NSQIP surgical risk calculator: a decision aid and informed consent tool for patients and surgeons. J Am Coll Surg. 2013;217: 833-42.e833.
2. Chudgar N, Yan S, Hsu M, Tan KS, Gray KD, Molena D, et al. The American College of Surgeons surgical risk calculator performs well for pulmonary resection: a validation study. J Thorac Cardiovasc Surg. 2022;163: 1509-16.e1.
See Article page 1509.

\section{Commentary: Numbers will tell their own story}

\author{
Waël C. Hanna, MDCM, MBA, FRCSC
}

In the realm of lung cancer, we collaborate with oncologists and health professionals from other disciplines to determine the best personalized care pathways for any individual patient. The conversation will often come down to the question of risk versus benefit. Is the risk of operation too high, and should we recommend nonsurgical treatment instead? The answer is almost always a story, told by a surgeon or a radiation oncologist, tainted by the most recent experience, or the most memorable one, where a patient did well or did not do well.

This is unlikely to be the case for much longer. In this issue of the Journal, Chudgar and colleagues ${ }^{1}$ validate the American College of Surgeons National Surgical Quality Improvement Program (ACS-NSQIP) surgical risk calculator in a population of patients undergoing lung cancer resection. In a retrospective sample of 2154 patients from the Society of Thoracic Surgeons database, they compare the projected risk of complications, based on the calculator, to the real outcomes after surgery. They find that the calculator performs very well in predicting the probability of the aggregate complication rate, serious complications, and

\footnotetext{
From the Division of Thoracic Surgery, McMaster University, Hamilton, Ontario, Canada

Disclosures: The author reported no conflicts of interest.

The Journal policy requires editors and reviewers to disclose conflicts of interest and to decline handling or reviewing manuscripts for which they may have a conflict of interest. The editors and reviewers of this article have no conflicts of interest.

Received for publication Feb 9, 2021; revisions received Feb 9, 2021; accepted for publication Feb 10, 2021; available ahead of print Feb 16, 2021.

Address for reprints: Waël C. Hanna, MDCM, MBA, FRCSC, Division of Thoracic Surgery, McMaster University, St Joseph's Healthcare Hamilton, 50 Charlton Ave, E Juravinski Tower, Suite T2105 F, Hamilton, ON, Canada L8N4A6 (E-mail: hannaw@mcmaster.ca).

J Thorac Cardiovasc Surg 2022;163:1519-20

$0022-5223 / \$ 36.00$

Copyright (c) 2021 by The American Association for Thoracic Surgery

https://doi.org/10.1016/j.jtcvs.2021.02.020
}

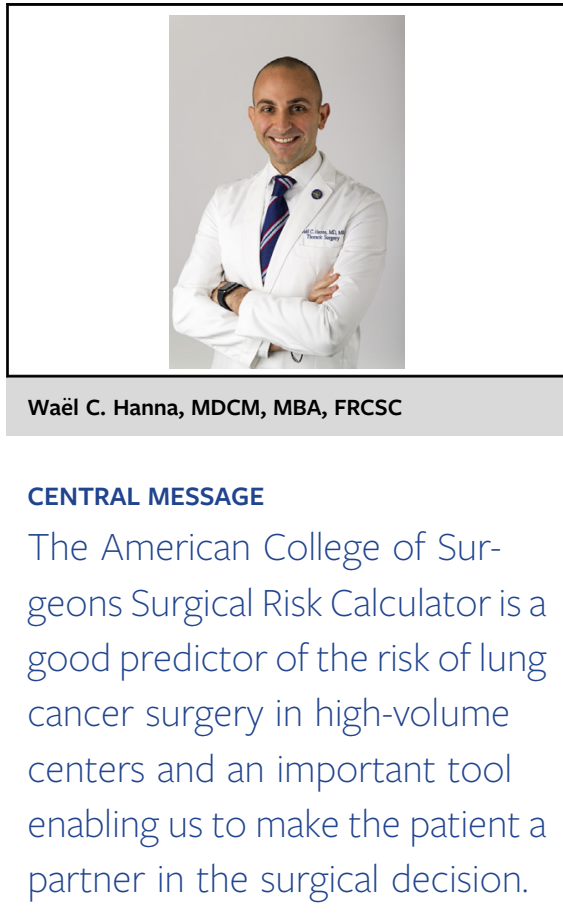

most of the individual complications. In other words, if any individual patient's demographic data are plugged into the calculator, the predicted risk of operation ends up being very close to the actual risk. Another example of how the crystal ball of big data can be used to aid decision making on the individual level.

Although this calculator has now been integrated in the decision making framework at the authors' home institution, whether centers with lower surgical volume are able to use this tool remains unclear. Because the risk calculator does not take into account hospital volume, this might not be possible to determine outside of a prospective trial. Many believe that volumes can be surrogates for overall team expertise in treating cancer. As such, it is also possible that the expertise of the authors' institution in optimal selection of patients for surgery may have resulted in good 